\title{
Performance of a 150-MW S-Band Klystron1
}

\author{
Stanford Linear Accelerator Center \\ Stanford University, Stanford, CA 94309
}

D. SPREHN, R. M. PHILLIPS, and G. CARYOTAKIS

\begin{abstract}
As part of an international collaboration, the Stanford Linear Accelerator Center (SLAC) klystron group has designed, fabricated, and tested a $60-\mathrm{Hz}, 3-\mu \mathrm{s}, 150-\mathrm{MW}$ S-band klystron built for Deutsches Elektronen Synchrotron (DESY). A test diode with a 535-kV, 700-A electron beam was constructed to verify the gun operation. The first klystron was built and successfully met design specifications. The 375-MW electron beam represents a new record for SLAC accelerator klystrons in terms of voltage, current, energy, and ruggedness of design The if output power is a $150 \%$ increase over the S-band tubes currently used in the two-mile-long linear accelerator at SLAC. This paper discusses design issues and experimental results of the diode and klystron.
\end{abstract}

\section{INTRODUCTION}

The Stanford Linear Accelerator Center (SLAC) klystron group is currently designing, fabricating, and testing high power klystrons which range from $477-\mathrm{MHz}$ to $11.424-\mathrm{GHz}$, and from 1-MW under continuous operation to $150-\mathrm{MW}$ at 3- $\mu \mathrm{s}$ pulsewidth. These klystrons power accelerators which are either operating, under construction, or will be used as test accelerators to study advanced concepts for future collider development.

The linear collider at SLAC uses S-band klystrons operating at $60-\mathrm{MW}$ peak output power. Due to the experience with constructing and operating hundreds of these tubes (known as $\mathbf{5 0 4 5}$ klystrons) it was decided to limit design parameters, such as gradients and cathode loading, to at or below the levels of the 5045. Due to the high power requirement of the 150-MW klystrons, the cathode current, gun convergence, beam current density and voltage, focusing field, pulse energy, and the power in the output cavity will be significantly higher than in a 5045. Some important design parameters are shown in Table 1.

${ }^{1}$ Work supported by the Department of Energy under Contract DE-AC03-76SF00515. 


\section{DISCLAIMER}

This report was prepared as an account of work sponsored by an agency of the United States Government. Neither the United States Government nor any agency thereof, nor any of their employees, make any warranty, express or implied, or assumes any legal liability or responsibility for the accuracy, completeness, or usefulness of any information, apparatus, product, or process disclosed, or represents that its use would not infringe privately owned rights. Reference herein to any specific commercial product, process, or service by trade name, trademark, manufacturer, or otherwise does not necessarily constitute or imply its endorsement, recommendation, or favoring by the United States Government or any agency thereof. The views and opinions of authors expressed herein do not necessarily state or reflect those of the United States Government or any agency thereof. 


\section{DISCLAMMER}

Portions of this document may be illegible in electronic image products. Images are produced from the best available original document. 
TABLE 1. Design parameters for the 150-MW kystron.

\begin{tabular}{|l|l|}
\hline Beam voltage & $535-\mathrm{kV}$ \\
\hline Beam current & $700-\mathrm{A}$ \\
\hline RF Pulsewidth @ rep rate & $3-\mu \mathrm{s}$ @ $60-\mathrm{Hz}$ \\
\hline Cathode loading & $2: 1 \quad\left(6-\mathrm{A} \mathrm{cm}^{2}\right.$ max $)$ \\
\hline Cathode convergence & $40: 1\left(5.25^{\prime \prime}\right.$ dia.) \\
\hline RF output power & $150-\mathrm{MW}$ \\
\hline Saturated gain & $\sim 55-\mathrm{dB}$ \\
\hline Efficiency & $\geq 40 \%$ \\
\hline Operating frequency & $2998-\mathrm{MHz}$ \\
\hline Solenoidal focusing field & $2100-$ gauss \\
\hline
\end{tabular}

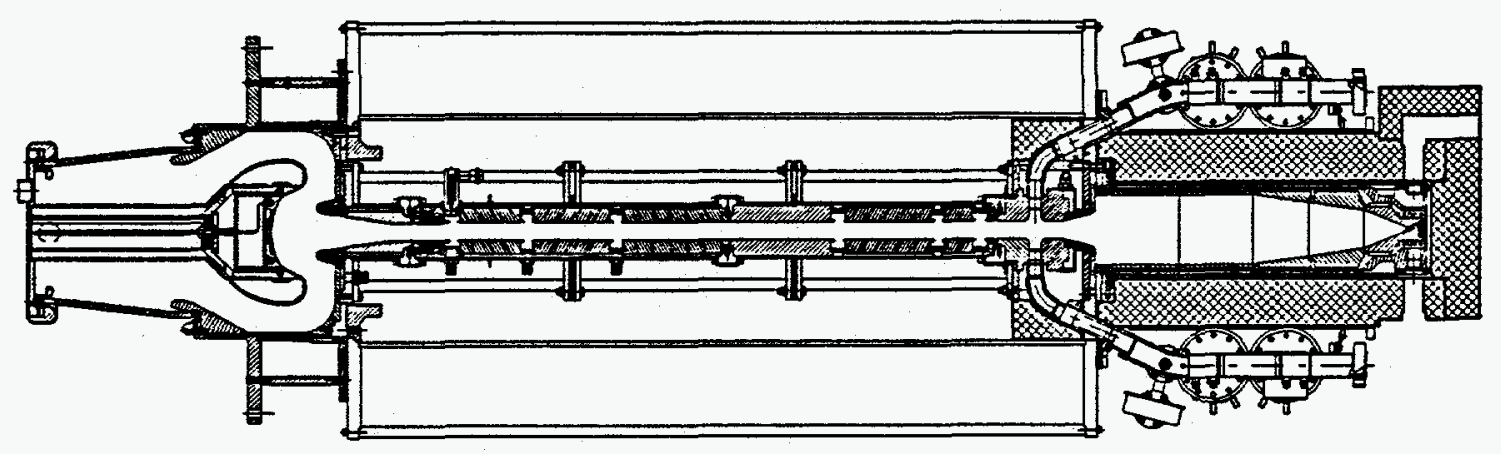

FIGURE 1. The 150-MW klystron assembly shown with magnets and lead.

The completed klystron stands 104 inches tall from the gun baseplate to the collector tip and weighs approximately 600 pounds. The klystron is inserted into a 15-kW solenoid and dressed with 3 to 4 inches of lead (Fig. 1).

\section{DESIGN}

With $40 \%$ efficiency desired, the $150-\mathrm{MW}$ klystron required a $375-\mathrm{MW}$ electron gun. A diode was first constructed to verify the gun operation. At 3- $\mu$ s operation the diode was processed to $500-\mathrm{kV}$ when if gun oscillations were detected. Despite the oscillations, the diode was operated for short periods of time at full power with $3-\mu$ s pulsewidth and $60-\mathrm{Hz}$, and up to $550-\mathrm{kV}$ at slightly shorter pulsewidths. The microperveance was measured at 1.78 with $99.8 \%$ beam transmission, which agreed well with design.

After discovery of the diode if gun oscillation, two changes were made to the klystron gun design. The gap suspected of coupling the $1.365-\mathrm{GHz}$ oscillation to the beam was shorted, and small strips of molybdenum were fabricated to short out another possible source of oscillation at the cathode heat shield gap. With these two exceptions, the klystron gun was copied directly from the diode. 


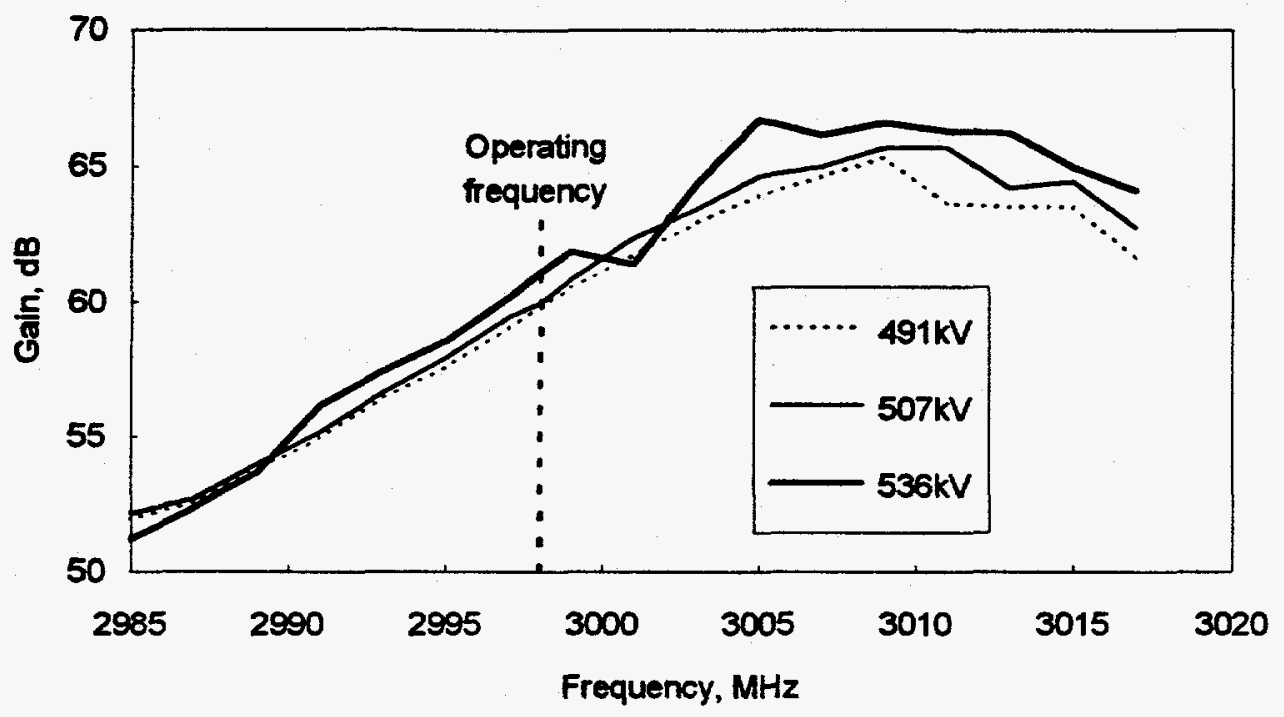

FIGURE 2. Small signal gain of the 150-MW klystron verses frequency.

\section{KLYSTRON EXPERIMENTAL RESULTS}

The small signal gain is slightly higher at $3.01-\mathrm{GHz}$ regardless of beam voltage settings (Fig. 2). Large signal data was not taken across such a wide frequency band. It was found that as the tube approached saturation, the optimum frequency appeared to drop. At $150-\mathrm{MW}$, the optimum frequency had fallen to $3.002-\mathrm{GHz}$, and the saturated gain was approximately $54-\mathrm{dB}$.

While operating at 3- $\mu$ s and certain combinations of magnetic field and beam voltage, an if oscillation would appear at the falling edge of the beam pulse which, if not checked by adjusting the magnetic field, lead to beam interception and gas formation. The frequencies of the oscillation were found to be $8.588-\mathrm{GHz}$ and the second harmonic at 17.18-GHz. Areas of oscillation are plotted which show measured edges of oscillation-free operation in solid tic marks (Fig. 3). The "cones" which expand upward and to the right are areas at which the oscillation occurred, weaker at the edges of the cones and stronger in the centers.

Theories concerning the if oscillation mechanism must include the periodicity with magnetic field and the frequency stability. One possibility is that a slightly off-axis beam is kicked further by an asymmetric mode in one cavity and spins around a certain number of times until it reaches the next cavity capable of being exited by an off-axis beam at approximately the same frequency. The signal feeds back to the first excited cavity via the drift tube and if enough time and gain are 
present, an oscillation builds up. As the magnetic field is increased, the beam spins around more, and soon the two cavities are no longer in a (azimuthal) phase relation which is synchronous. When the magnetic field is increased enough, the beam has spun around one extra revolution and the cavities are again in phase and the oscillation can again occur. Despite the mechanism, stable operation of the klystron requires keeping the operating parameters within a safe "channel" between the oscillation cones.

Klystron performance indicated that the tube was capable of more than 150-MW. The if output power versus if input power clearly shows that operation

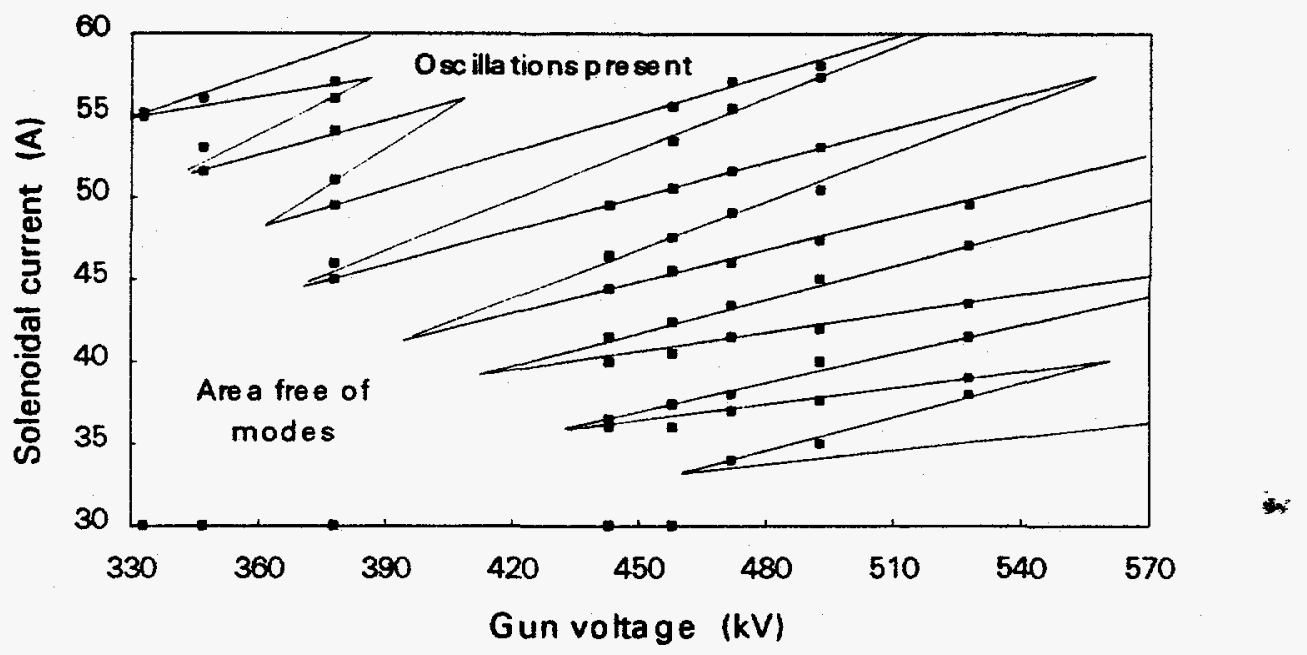

FIGURE 3. Area of kystron self-oscillation at $3 \mu$ s operation. Coil current of 45A corresponds to an 1800 gauss axial field.

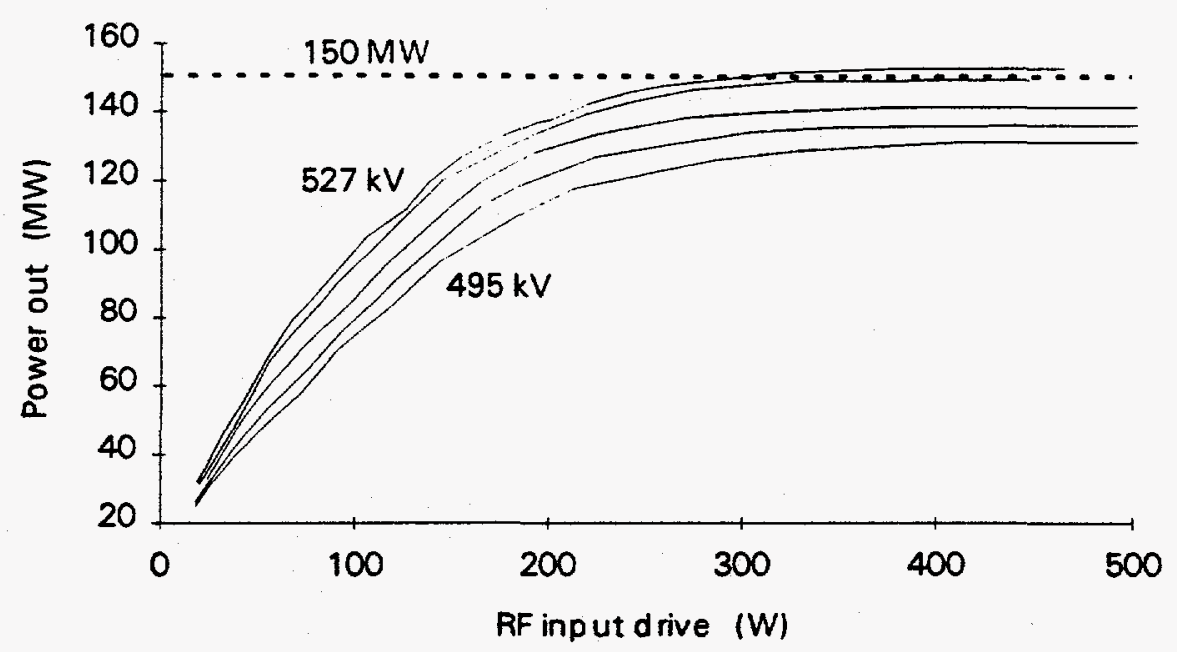

FIGURE 4. Measured output power versus drive of the 150-MW klystron at 527, $523,511,503$, and 495-kV ( $\mu \mathrm{K}=1.8, B z=1800-g, \tau=3-\mu \mathrm{s}$, Rep rate $=60-\mathrm{Hz})$. 


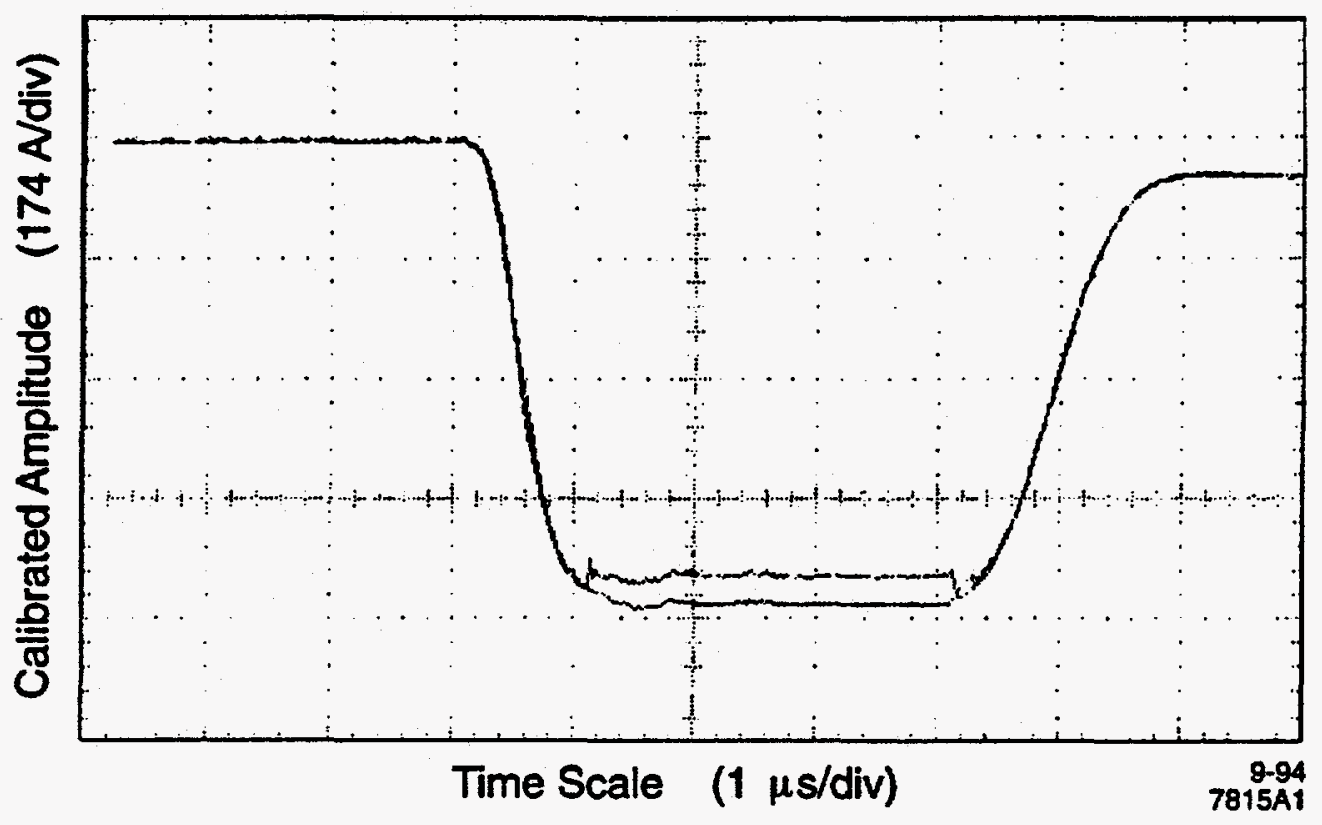

FIGURE 5. Typical collector current waveforms with if on and off (150-MW, 3- $\mu$ s, 60$\mathrm{Hz}, 1800$ gauss).

beyond 150-MW is possible (Fig. 4). Calorimetric data, collector and gun current, pulse transformer primary and secondary voltage values, crystal detectors, and an If power head were verified against each other and power balances compared.

The electron beam was noticeably intercepting the drift tube when output power exceeded approximately 100-MW. CONDOR simulations at peak output power predicted that 30 to 40 -A would be collected on the drift tube shortly after the output cavity (1). Collector current data taken when the rf output is at $150-\mathrm{MW}$ and when the if is off, agree well with simulation. Interception is on the order of $40-\mathrm{A}$, or $5.7 \%$ of the total current (Fig. 5). According to calorimetric readings taken during operation at $3 \mu \mathrm{s}$ at $150-\mathrm{MW}$ rf, the intercepted beam power was approximately $2 \%$ of the collector power. With less than 100-MW if applied, the transmitted beam power was approximately $99.6 \%$. This means that the intercepted current at high if power levels consists mainly of low energy electrons with an average energy of approximately $100-\mathrm{kV}$.

Output power was measured by calibration of a waveguide coupler and using detector crystals or a peak power analyzer. Instrumented water loads were used to absorb the if and gave lower values of total power than did the waveguide couplers. To be conservative, the waveguide coupler calibrations were derated to the calibration of the water loads and essentially used for indicating pulse shape. On a 1-dB per division scale, the output pulse is quite flat, having less than $0.25-\mathrm{dB}$ variation across the pulse top for 3- $\mu$ s duration (Fig. 6). 


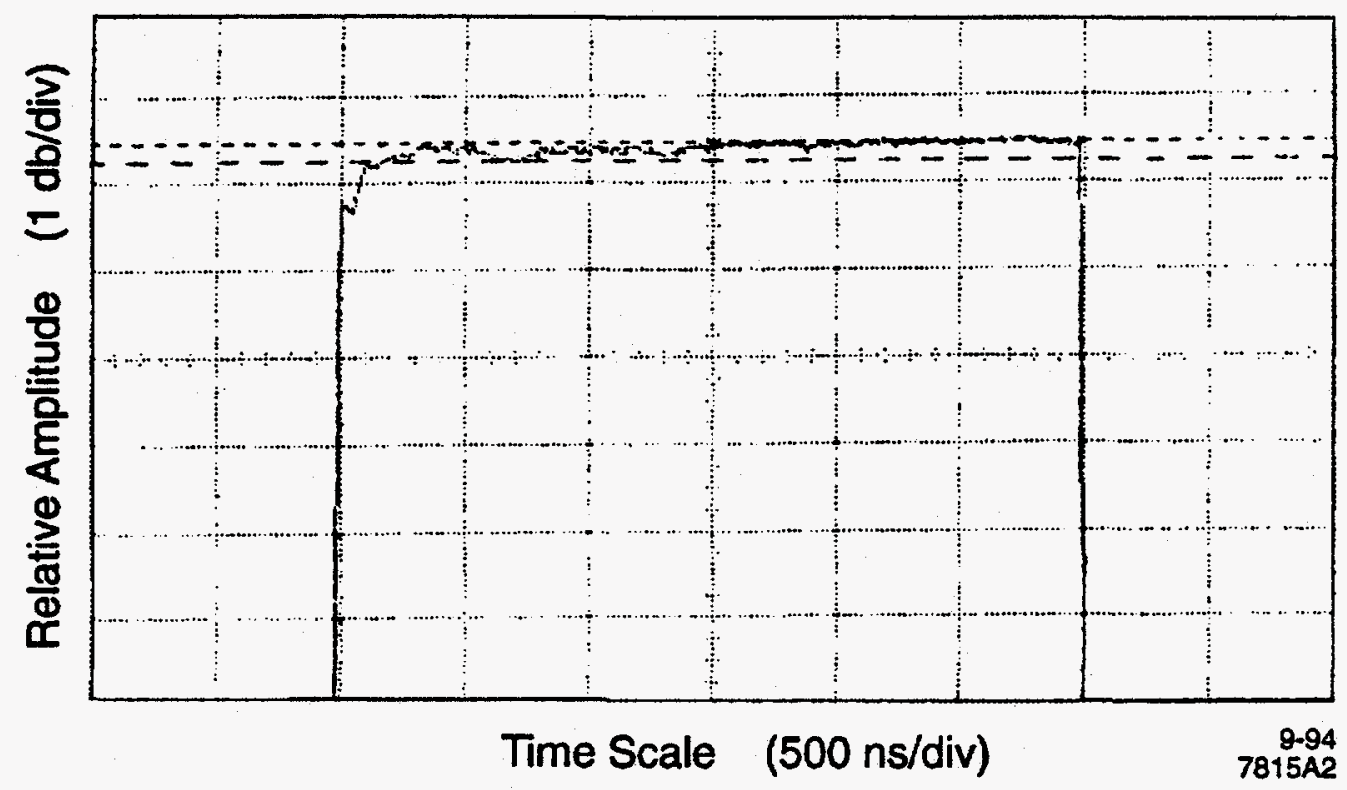

FIGURE 6. Detected if output power from peak power analyzer at 150-MW operation.

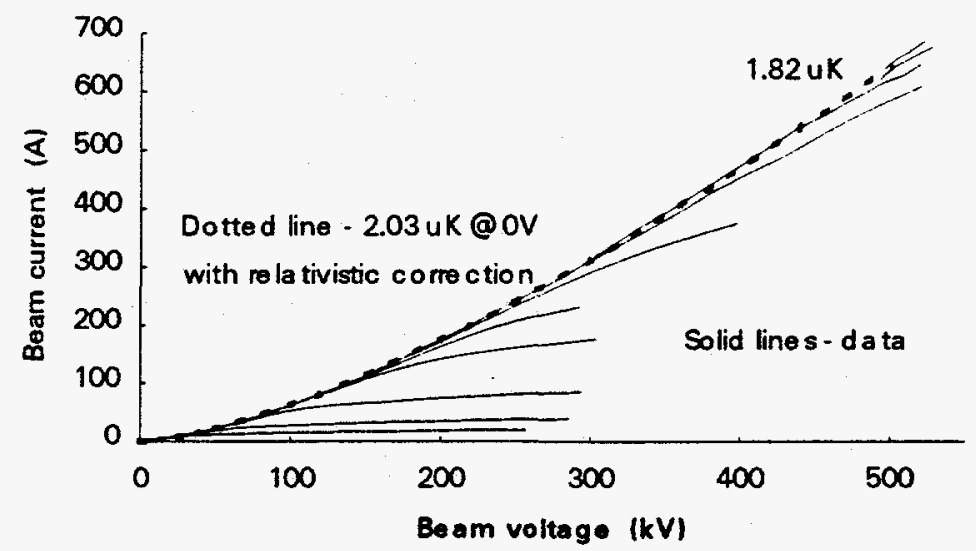

FIGURE 7. Klystron beam current and voltage data showing gun microperveance is $\sim 1.82$ at the design voltage of $535-k \mathrm{~V}$.

The klystron gun performed similarly to the diode gun when temperature data is extrapolated and plotted with microperveance. At low beam voltages where relativistic effects are negligible, the microperveance is approximately 2.03 , while at higher levels it falls toward 1.82 (Fig. 7). The slight difference in microperveance from the diode values can be attributed to mechanical tolerances and assembly procedures. The cathode heater required more power for a given cathode temperature due to the inchusion of the molybdenum shorting strips at the cathode edge. 


\section{FURTHER WORK}

The second 150-MW klystron is currently under final construction at SLAC. There are three differences between the first and the second klystrons. To increase efficiency a two-cell output cavity structure will be used instead of a single gap. To increase life expectancy of the cathode if temperature-limited operation is desired, a scandate cathode will be used. Instead of copper drift tubes, two threaded and sandblasted stainless steel drift tubes will be inserted between cavities 3 and 4 , and 4 and 5. The new drift tubes should increase the attenuation of if modes traveling in the drift tube and thereby reduce the coupling between the three cavities. The added loss should either eliminate the oscillations shown in Fig. 3 altogether, or increase the threshold of oscillation and allow for more stable operation. Testing of the second klystron is scheduled to begin early in 1995.

\section{ACKNOWLEDGMENTS}

This work is sponsored by Deutsches Elektronen Synchrotron in Hamburg, Germany as part of a collaboration towards development of future colliders, and is supported by the Department of Energy under Contract DE-AC03-76SF00515. Thanks go to Saul Gold and Ron Koontz for their work on the modulator, Mike Harding and Eric Jongewaard for mechanical design, Bernd Krietenstein for his MAFIA simulations, Erling Lien and George Miram for their work on the buncher, gun and many informative discussions. Discussions with Ken Eppley, Randy Fowkes and Ed Wright are gratefully acknowledged.

\section{REFERENCES}

1. B. Aimonetti, S. Brandon, K. Dyer, J. Moura, D. Nielsen Jr., CONDOR user's guide, Lawrence Livermore Nat'l Lab., Livermore Computing Systems Document, April 1988. 